\title{
The Medical Context of Parental Coping With Childhood Cancer ${ }^{1}$
}

\author{
Oscar A. Barbarin² and Mark Chesler \\ University of Michigan
}

This research assessed the extent to which contextual factors, especially the medical context, are related to the use of specific coping strategies by 74 parents of surviving children with cancer. Parents reported that they coped reasonably well by using information-seeking, problem-solving, help-seeking, maintaining emotional balance, relying on religion, being optimistic, denying, and accepting. More highly educated parents tended to use problem solving, optimism, and information seeking significantly more and denial significantly less than less well-educated parents. However, gender and income were unrelated to coping. The use of specific coping strategies was not related to severity of the child's medical condition, stress level, or parents' own evaluations of their coping effectiveness. However, the quality of relations with the medical staff was strongly related to coping strategies. Use of passive coping strategies was positively related to good relations with the medical staff.

Most studies of stressful life events indicate that illness or loss of a loved one represents a major stressor (Dohrenwend \& Dohrenwend, 1974; Dohrenwend, Krasnoff, Askenasy, \& Dohrenwend, 1978; Holmes \& Rahe, 1967). Although diagnosis and treatment of a child with a serious and chronic illness seldom appears in such studies, it also represents a significant life disruption which threatens personal equilibrium and family well-being. The initial impact of the diagnosis is illustrated in the following reports from parents.

\footnotetext{
${ }^{1}$ Preparation of this paper was greatly facilitated by the award of a postdoctoral fellowship by the Psychology Department at Stanford University and by a grant from the University of Michigan's Committee on the International Year of the Child. Thanks are due to Professors Philip Zimbardo and Ewart Thomas.

${ }^{2}$ All correspondence should be addressed to Oscar A. Barbarin, Department of Psychology, University of Michigan, Ann Arbor, Michigan 48109.
} 
It tore me up. I didn't know from one minute to the next whether he was going to be with us. You know I worried a lot. I felt bad. I was hurt. He is my only boy. I didn't know if I was there myself.

I felt like my heart had been torn right out of me. I was terribly despondent at first.

I was bitter and asked myself why it had happened.

Although medical progress has increased the likelihood that a child diagnosed with cancer will survive and resume a normal life (American Cancer Society, (1982), many children still die from the disease. Painful medical treatments (perhaps surgery) and their side effects, repeated hospitalizations, and the uncertainty of recovery or relapse, of life or death severely tests parents' emotional stability (Futterman \& Hoffman, 1973). Moreover, many parents' lack of familiarity with the disease and its treatment, concern about insurance coverage and finances, and the unremitting demands of caring for a seriously ill child all create stress (Desmond, 1980). The effort required to develop and nurture relationships with family, friends, and medical professionals may further tax parents' psychological reserves (Binger et al., 1969; Cassileth \& Hamilton 1979). Although some of these stresses may diminish over time, they seldom vanish entirely.

\section{STRESS AND COPING STRATEGIES}

Several scholars suggest that variations in families' experience of stress is related to differences in their use of coping strategies (Barbarin, 1983; Brehm, 1965; Kubler-Ross, 1978; Lazarus, 1966; Seligman, 1975; Taylor, 1983). Our understanding of parents' strategies for coping with the stresses of childhood cancer has been advanced substantially by several pioneering studies. For instance, Friedman, Chodoff, Mason, and Hamburg (1977) documented the use of acceptance, resignation, religious faith, hope and optimism, denial, and anticipatory grief by families of children with cancer. Spinetta, Swarner, and Sheposh (1981) observed several other coping strategies among such families: a consistent philosophy/theology, support from a significant other, communication with the child, communication with siblings, and maintenance of normal family functioning. Kupst et al. (1982) categorized the coping strategies they observed somewhat differently: open communication, living in the present, affirming life, treating the child as normal, and developing a philosophical outlook on the disease.

Although these descriptive typologies advance our understanding of how families actually deal with serious and chronic childhood illness, they do not take advantage of recent conceptualizations of the coping process. Lazarus and Launier (1978) proposed a typology of coping strategies based on the distinction between active or problem focused (e.g., direct action aimed at eliminating or mitigating anticipated stresses) and passive or emotion-focused 
(e.g., cognitive or emotional maneuvers aimed at moderating the impact of stress by reinterpreting or avoiding it). Although Billings and Moos (1981) made finer discriminations between the method (active/direct vs. passive/indirect) and the target (problem vs. emotions) their ways of classifying discrete coping strategies are consistent. In these terms, both the list developed by Friedman et al. (1977) and Kupst et al. (1982) emphasized relatively passive strategies. Spinetta et al. (1981) included some strategies that are more active in nature: For example, support, communication, and maintenance of family functioning. Unfortunately, there are few data available from these and other sources to assess the factors that may predispose parents to use various active or passive strategies. Most importantly, few studies have examined the relationship between the medical factors and coping process.

\section{The Medical Context of Parental Coping}

Early analyses of the relationship between parental coping strategies and the medical context relied primarily on observations of parents of dying children and took the form of prescriptive reports. More recent studies that have explored medical context effects typically have examined only the child's medical condition (Spinetta et al., 1982). Attention to the child's medical condition is understandable. Indeed, parents' coping responses can be expected to vary with the child's diagnosis and medical status because the latter are associated with differential stress, prospects for survival, and intrusiveness of treatment (Chesler, Barbarin, Chesler, Hughes, \& Lebo, 1981). For example, children with Wilms tumors now have a 2-year survival rate of over $85 \%$, whereas children with brain tumors have a 2-year survival rate of under 50\% (American Cancer Society, 1982). Varied treatment procedures such as surgery, radiation, or chemotherapy create quite different concerns and require somewhat different adaptations by parents and children. Similarly, uncontrollable events such as relapse usually creates additional severe stress and uncertainty. Learned helplessness theory (Seligman, 1975) predicts that the more severe and uncontrollable the stressor the more likely individuals are to adopt passive and emotion-focused coping strategies such as acceptance, optimism, and religious beliefs. This prediction is consistent with the emphasis on passive strategies observed by Friedman et al. (1977) and Kupst et al. (1980).

However, the child's medical situation is only part of a more complex medical context which includes evolving relations with a medical care organization. Although the link between coping and transactions with important others has been noted elsewhere (Brickman et al., 1982; Coyne \& Holroyd, in press; McCubbin \& Patterson, 1982, 1983; Wortman \& DunkelSchetter, 1979), few studies have explicitly examined the interaction between parents' ways of coping and their relationship with medical staff. Much of 
the prior research has been conducted by staff responsible for the medical or psychological care of children with cancer. As such, the staff's impact on stress and coping has been taken as a given and not examined systematically.

In general, the role structure of bureaucratized medical care systems press for compliant and relatively passive patient/parent roles (Antonovsky, 1980; DiMatteo, 1979; Friedson, 1970; Stone, 1979; Taylor, 1979). In this context, passive strategies such as deference, optimism, and denial, and reliance on religious faith may be regarded by the staff as most appropriate or convenient behaviors for patients and their families. The use of active coping strategies by patients and their guardians, such as information seeking and participation in decision-making, may be construed as acting-out responses or as intrusions on the medical staff's responsibilities. In addition, medical staff may avoid constantly depressed or hopeless parents, just as they appear to withdraw emotionally from their young patients and families as death approaches (Binger et al., 1969; Vaux, 1977). Since the causal direction of the relation between parental coping and staff behaviors is unclear, it is also possible that parents' coping choices may influence the ways in which medical staff relate to parents.

An examination of the relations between parent-staff transactions and parents use of particular coping styles may offer valuable insights into why parents respond they way they do in chronically stressful situations. In this paper we examine how the various coping strategies covary with aspects of the medical context. The medical context is conceived in terms of the child's medical condition, parental stress from the illness, and the quality of parent's relationships with the medical staff. Figure 1 presents the variables and the relationships explored in this study.

This research is part of a larger study of stress and coping in families of children with cancer. In the larger study, a total of 94 parents ( 55 families) were sampled from a pool of 265 families of children with cancer treated within the previous 5 years at a major university medical center. This sample population was selected randomly, after stratification by the age and life status of the child at the time of the study and by the type of cancer sustained by the child. In all, 70 families were contacted and 15 declined to participate.

Participants in this study include 74 parents from 45 families with children living with cancer; 42 mothers and 32 fathers. With the exception of one black family all participants were white. Twenty-three percent of the parents of children living with cancer reported an annual family income of less than $\$ 15,000,29 \%$ had an annual income between $\$ 15,000$ and $\$ 25,000$, and $36 \%$ an annual income over $\$ 25,000 ; 11 \%$ of the informants did not report their annual income. Ages of the wives ranged from 23 to 54 years 
Medical Context

\begin{tabular}{|ccc|}
\hline A. & B. & C. \\
Child's & Medical & Parent - \\
Condition & Stress & Staff \\
& & Relations \\
\hline
\end{tabular}

Coping

A. Strategies

•active

-passive

B. Effectiveness

Social Status

\section{Gender}

Education

Income

Fig. 1. Relationship between medical context and parental coping.

with a median of 35 ; husbands' ages ranged from 28 to 57 with a median of 38. The major forms of childhood cancer represented in this analysis included leukemias $(33 \%)$, lymphomas $(19 \%)$, cancer of the nervous system $(18 \%)$, osteogenic sarcomas $(12.5 \%)$, Wilms' tumor $(11 \%)$, and miscellaneous others $(6.5 \%)$.

\section{Measures}

Extensive individual interviews using both open-ended and structured formats, and lasting from 60 to $90 \mathrm{~min}$, were conducted by trained graduate and undergraduate psychology and sociology students. The interviews covered parents' experience with and reactions to their child's illness: the history and course of the illness, initial reactions, how individuals and the family coped over time, the impact of the illness on the family, and the relationship between the family and the medical staff, extended family, friends, and school personnel. Interviews were audiotaped, typed, and later coded by several independent raters. A structured questionnaire with 3- and 5-point Likert-type rating scales also was completed by the parents and mailed back several days following the personal interview. Ninety percent of the parents who were 
interviewed completed and returned the questionnaire. The high return rate is due in part to the strong endorsement of the study by Share, a Candlelighteraffiliated self-help group for families of children with cancer and by the parents' view that information about their experiences might be helpful to newly diagnosed families.

Medical Context. The child's medical condition was assessed by parents' interview reports of the number of hospitalizations experienced after diagnosis and initial treatment induction. Parents' medically related stress was assessed by a composite index consisting of four items rated on a 3-point scale indicating the degree of stress resulting from (a) the fact that my child has cancer, (b) my child's reactions to drugs, (c) my fear of the child's death and, (d) my fear of relapse. The correlations among these items range from .47 to .63. The estimate of internal consistency is high (Cronbach's alpha $=.83$ ).

Parents' assessment of the quality of relations with medical staff was a composite measure developed by combining structured questionnaire ratings of relationship qualities such as respect, tenseness, anger, liking, and support. This index includes (a) Respect for Medical Staff, a 5-point rating of the effect of the illness on respect for medical staff $(1=$ much less, $5=$ much more); (b) Tension in Relations with Medical Staff, a 3-point rating of stress resulting from tense relations with medical staff, (c) Support From Medical Staf, a composite of two 5-point ratings indicating support received from doctors and from nurses (Pearson $r=.61, p<.001$ ); (d) Anger Toward the Medical System, a 5-point rating indicating the extent to which the experience of childhood cancer resulted in more or less anger toward the medical care systems; and (e) Liking the Medical Staff, a 5-point rating of change in feelings about medical staff resulting from the illness experience. This index represents parents evaluation of the relationship quality along several related but distinct lines. The combination of static ratings such as those of tension and support with change measures of liking, anger, and respect is justified by the strong correlations among these ratings (range $=-.35$ to +.71 ). These correlations show that individuals who report increases in liking and respect and decreases in anger are also likely to make favorable static ratings of support and tension. The static ratings and parents view of the change resulting from the intensive interaction during the treatment phase provide slightly different slants on parents' evaluations of the relationship. Moreover, the estimate of internal consistency supports the reduction of these ratings into a single index (Cronbach's alpha $=.76$ ).

Coping. Guided by earlier work on stress and coping, a typology of coping strategies was developed inductively from parents' actual feelings and behaviors reported in the interviews. Specific measures of coping techniques were generated from parents' responses to interview questions about how they coped with the diagnosis, treatment, treatment side effects, and the entire illness situation. A score for each of eight coping strategies was obtained 
by tabulating each instance in which a parent indicated use of a particular strategy. The range of scores on each strategy is 0-4 except for religious faith (range $=0-10$ ), which has several additional items specifically addressing the role of religion in coping. The interrater agreement for the coding of the strategies included in the typology is .83. The eight coping strategies and two coping styles are as follows:

1. Information seeking involves parents seeking and using information to help them understand the meaning of the diagnosis, to place their emotional reactions to the illness in perspective, or to reduce uncertainty and fear regarding their child's survival.

I tried to find out everything I could about it. I read everything I could about it. The things I read about medical technology and its advances have helped me through the hard times. I keep some of these articles close at hand whenever I feel down.

2. Problem solving refers to the use of behaviorally oriented solutions for specific problems, such as increased work hours to raise money to meet medical expenses, rearranging schedules to be with the child in the hospital, or planning with teachers for the child's return to school.

Its like solving a problem. I am going to solve that problem, and I will not allow certain things to happen. I don't know how to describe the strength within a human individual except that I said I was stronger than whatever that problem is and I will prevail.

She was in great pain, and I didn't think they cared very much. I got their attention and they finally did something for the pain.

3. Informal help seeking refers to the self-initiated use of informal helping networks of family members and friends for instrumental aid or emotional support.

Friends and family are very important. I don't know if we could have handled it as well without the support of our friends and family. Other people are not quite as involved, and sometimes you need to talk with them. It was too much of a burden for me so I turned to my family, I turned to my friends, I turned to my co-workers.

4. Maintainance of emotional balance refers to active efforts designed to moderate emotional reactions and to avoid extreme mood swings, especially through cognitive self-control and related behaviors. In some sense it means trying to retain or recapture some degree of previous normality in one's personal style and social relations.

I try to see that the hustle and bustle of life is not important. I'm trying to take each day as it comes and to experience each day more. I've often practiced hypnotherapy and relaxation techniques, and I also use a little rationalization.

5. Reliance on religious beliefs/faith refers to the use of prayer and religious interpretations for emotional comfort or to evolve an acceptable explanation for the illness. 
I think praying had done more than anything else. I practice my belief more. I feel that was the only place I could turn to get help when I really needed it. My religious beliefs have helped me.

6. Optimism involves the use of ideations or self-statements that things will turn out well and represents an effort to focus on positive rather than negative possibilities.

After the initial shock and everything we looked to the brighter side. Now we are not the scared of it.

I think positively. I think in terms of her growing up and going to school and getting better and doing the things that a normal child would do. We're preparing her for the future.

7. Denial refers to disbelief of the diagnosis or its negative implications, refusal to focus on illness-related issues and withdrawal from situations reminiscent of the illness. In the abstract it may be difficult to draw the line between optimism and denial but most reports do permit such distinctions.

My husband doesn't want to know about our son having to go to the hospital prior to when he has to go. It was 2 weeks before he could pronounce the word leukemia.

I try to keep my mind off it. I don't watch TV shows or anything pertaining to it. I shut it off. I don't want to hear about it. Why hurt yourself by watching that garbage?

8. Acceptance refers to a response characterized by a somewhat fatalistic perception of a situation as inevitable and uncontrollable. It represents coming to terms with a problem without acting directly on it.

I've always said that 'If it's gonna happen, it's gonna happen.'

Why should I cry? I just handled it and accepted it and that was that.

9. Active coping styles represent a composite index formed by summing the scores of coping strategies judged to be active in orientation (nos. 1-4 above).

10. Passive coping styles represent a composite index formed by summing the scores of coping strategies judged to be passive in orientation (nos. 5-8 above).

Coping effectiveness was based on a 4-point rating made by informants of how well they felt they handled their child's illness $(1=$ poorly, $4=$ very well).

Social Status. The social demographic variables used in this study include gender, years of formal education, and annual family income. For chisquare analyses parents are divided into three income groups based on their reported total family income ( $<\$ 10,000, n=13 ; \$ 10-\$ 25,000, n=26$; and $>\$ 25,000, n=23$ ) and into three groups based on years of formal educa- 
tion (high school education or less, $n=24$; some college, $n=20$; and college graduate or more, $n=23$ ).

\section{RESULTS}

Most parents felt that they coped reasonably well. Of the 74 parents in the sample only one gave herself a poor rating, $13(17.6 \%)$ gave themselves fair ratings, $42(56.8 \%)$ gave themselves good ratings, and $18(24.3 \%)$ gave themselves excellent ratings. Table I presents correlations among the coping strategies. This table clearly shows that the specific coping strategies are not highly correlated with one another. These correlations are low to moderate, with a range of -.36 to +.19 . The highest correlation occurs between Acceptance and Problem solving and suggests, reasonably enough, that engagement in active efforts to solve instrumental problems of the illness is inconsistent with passive acceptance of the situation. Table II presents the correlations among the four measures of medical context. None of the correlations is significant.

\section{Demographics, Coping Strategies, and Medical Context}

In order to assess the effects of potentially mediating variables, correlations or chi-square were computed between demographic variables and measures of medical context. Demographic and situational variables tested include the amount of medical stress, time spent by parents in the hospital, number of child hospitalizations, diagnostic of category of the child, gender, education, and income. A significant correlation was found between education and the quality of relations with medical staff $(r=-.43, p=.0002)$. More highly educated parents reported poorer relations with the medical staff

Table I. Pearson Product-Moment Correlation Matrix for Parental Coping Strategies

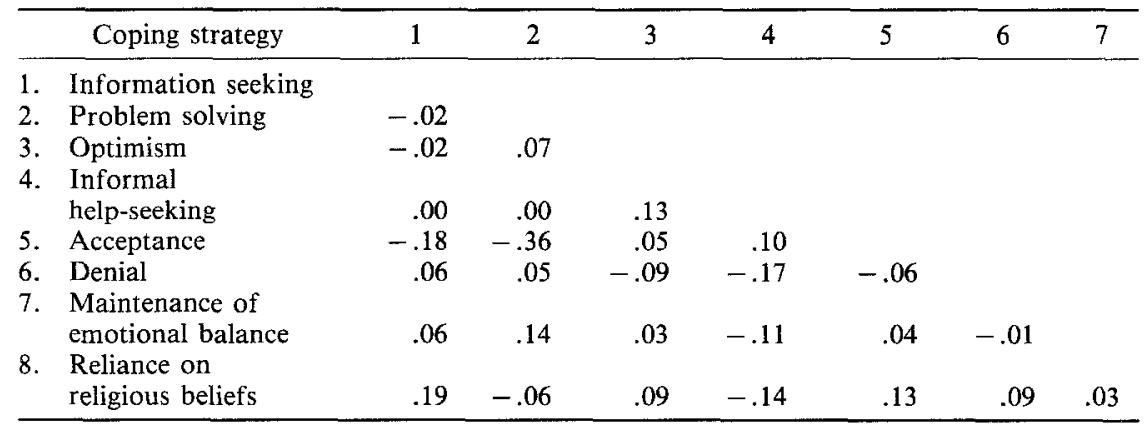


Table II. Correlation Matrix for Measures of Medical Context

\begin{tabular}{lrrrr}
\hline \multicolumn{1}{c}{ Variable } & 1 & 2 & 3 & 4 \\
\hline 1. $\begin{array}{l}\text { Relations with the } \\
\text { medical staff }\end{array}$ & - & & & \\
2. $\begin{array}{l}\text { No. of hospitali- } \\
\text { zations }\end{array}$ & -.11 & & & \\
3. $\begin{array}{l}\text { Medical stress } \\
\text { 4. Coping effectiveness } \\
\text { (self-rated) }\end{array}$ & .09 & -.06 & & \\
\hline
\end{tabular}

than parents with less education. MANOVA were used to asess sex, income, and education differences in the use of coping strategies. No significant differences are found with respect to gender (multivariate $F(8,59)=1.32, p$ $=\mathrm{ns}$ ), income (multivariate $F(16,94)=0.555, p=\mathrm{ns}$ ). However, multivariate analysis suggests that education approaches significance (multivariate $F(16,114)=1.64, p=.07$ ). Table III represents the means for each of the education groups on the coping strategies assessed in the MANOVA analyses.

Because the multivariate $F$ failed to reach an acceptable level of significance no follow-up of analyses were computed to determine the specific coping strategies along which the education groups differed. However, parents level of education was positively correlated with the use of problem solving $(r=.30, p<.02)$, information seeking $(r=.29, p<.02)$ and optimism $(r=.26, p<.03)$ and is negatively correlated with the use of denial $(r=$ $-.26, p<.03)$. Moreover, parents level of education is strongly positively correlated with the composited index of active coping styles $(r=.49, p<$ $.001)$.

Table IV presents the regression coefficients and the zero-order correlations between the coping strategies and four measures of medical con-

Table III. Results of MANOVA Analyses Comparing Coping Strategies by Educational Groups

\begin{tabular}{lccc}
\hline Coping strategies & $\begin{array}{c}\text { High school } \\
(n=24)\end{array}$ & $\begin{array}{c}\text { Some college } \\
(n=20)\end{array}$ & $\begin{array}{c}\text { College graduate } \\
(n=23)\end{array}$ \\
\hline Information seeking & 1.21 & 1.35 & 1.52 \\
Problem solving & 1.38 & 1.60 & 1.83 \\
Help Seeking & 1.13 & 1.10 & 1.26 \\
Emotional balance & 1.58 & 1.85 & 1.43 \\
Religious beliefs & 4.79 & 9.05 & 6.00 \\
Optimism & 1.42 & 1.55 & 1.78 \\
Denial & 1.67 & 1.50 & 1.30 \\
Acceptance & 1.79 & 1.70 & 1.57 \\
\hline
\end{tabular}


Table IV. Regression Coefficients and Zero-Order Correlations Between Coping Strategy, Education, and Measures of Medical Context

\begin{tabular}{lcccc}
\hline & \multicolumn{4}{c}{ Criterion measures } \\
\cline { 2 - 5 } \multicolumn{1}{c}{ Variable } & $\begin{array}{c}\text { Hospitali- } \\
\text { zation }\end{array}$ & $\begin{array}{c}\text { Medical } \\
\text { stress }\end{array}$ & $\begin{array}{c}\text { Parent- } \\
\text { staff } \\
\text { relations }\end{array}$ & $\begin{array}{c}\text { Coping } \\
\text { effective- } \\
\text { ness }\end{array}$ \\
\hline $\begin{array}{l}\text { Coping strategy } \\
\text { Information seeking }\end{array}$ & .05 & .01 & -.13 & .00 \\
Problem solving & -.01 & .08 & $-.24^{a}$ & -.05 \\
Help seeking & -.18 & .04 & -.04 & .08 \\
Emotional balance & .09 & -.06 & -.13 & -.05 \\
Religious beliefs & -.07 & .15 & .18 & -.17 \\
Optimism & -.04 & -.06 & -.06 & .09 \\
Denial & .02 & -.08 & .03 & $.26^{a}$ \\
Acceptance & $-.24^{a}$ & .06 & $.48^{b}$ & .14 \\
Education & -.18 & -.17 & $-.43^{c}$ & .08 \\
Multiple $r$ & .32 & .21 & .65 & .38 \\
$F$ value & .90 & .38 & 4.76 & 1.36 \\
\hline${ }^{a} p \leq .05$. & & & & \\
${ }_{b} p \leq .01$. & & & & \\
${ }^{c} p \leq .001$. & & &
\end{tabular}

text used as criteria in the multiple regression analyses. The coping strategies as a group do not significantly relate to hospitalization, $F(8,65)=0.90$, $p=$ ns, parental medical stress, $F(8,65)=0.38, p=n$ s), or self-rated coping effectiveness, $F(8,65)=1.36$. However, coping strategies are strongly related to the quality of relations with medical staff, $F(9,57)=4.76, p=$ .0001 .

These data provide modest evidence of some relationships between measures of the medical context of coping and parents' use of specific coping strategies. Although parents' reports of disease-related stress does not demonstrate a significant relationship with any of the coping strategies, it appears that as the number of hospitalizations increases, parents are less likely to employ acceptance as a coping strategy. Parents reports of quality of relations with medical staff is positively correlated with acceptance and negatively correlated with problem-solving.

There also is a significant positive correlation between denial and selfevaluated coping effectiveness. Perhaps parents feel they are coping better to the extent they can deny the seriousness of their child's illness and its implications, buffering themselves from painful realities.

The results of the multiple regression of coping strategies on relations with medical staff are presented in Table V. In order to control for the mediating role education may have in the relationship between coping styles and relations with the medical staff, education was included among the predic- 
Table V. Multiple Regressions using Quality of Relations with Medical Staff as the Criterion and Coping Strategies and Education as the Predictors

\begin{tabular}{lccc}
\hline \multicolumn{1}{c}{ Variable } & $\begin{array}{c}\text { Partial } \\
\text { correlation }\end{array}$ & $\begin{array}{c}\text { Beta } \\
\text { coefficients }\end{array}$ & $t$ value \\
\hline Coping strategy & & & \\
$\quad$ Information seeking & .10 & 0.90 & 0.73 \\
Problem solving & .09 & 0.78 & 0.50 \\
Help seeking & -.10 & -1.26 & -0.74 \\
Emotional balance & -.28 & -1.82 & $-2.16^{a}$ \\
Religious beliefs & .10 & 0.25 & 0.79 \\
Optimism & .09 & 0.60 & 0.65 \\
Denial & -.06 & -0.46 & -0.46 \\
Acceptance & .45 & 3.99 & $3.83^{b}$ \\
Education & -.44 & -2.11 & $-3.68^{b}$ \\
\hline${ }^{a} p \leq .05$. & & & \\
${ }^{b} p \leq .01$. & & &
\end{tabular}

tor variables. Together education and coping strategies account for $43 \%$ of the variance in relations with the medical staff. The coping strategies which contribute most strongly to the prediction of relationship with the medical staff are acceptance (partial $r=.45$ ) and emotional balance (partial $r=$ -.27 ). Note that once education (partial $r=-.44$ ) is entered into the regression problem-solving is no longer significant.

\section{DISCUSSION}

These data partially support the argument that the medical context is related to individual coping strategies. Coping strategies are not strongly related to the child's medical situation nor to the degree to which parents experience illness-related stress. Thus, contrary to predictions of learned helplessness, high degrees of medical stress are not related to the adoption of a passive coping style. If anything, the more the child was hospitalized, the less likely parents were to accept the situation passively. Coping strategies are not related strongly to how parents evaluate their coping effectiveness but are related strongly to the quality of their relations with the medical staff. Parents who adopted passive coping strategies tended to be less well educated and to have better relations with medical staff than parents who did not.

Several caveats must be observed in interpreting these data. First, the data are generated by interviews with parents whose children all were treated at a single large teaching facility with few psychological support services (at the time of study). The results might be different in a smaller community hospital or in a setting that routinely provides extensive psychosocial ser- 
vices. Thus as the medical context itself varies, parents' reactions to the context may vary as well.

Second, the coping indices are derived inductively from clusters of parents's responses to open-ended questions rather than from explicitly structured ratings of coping. The approach adopted has the advantage of phenomenological validity, insofar as parents described what they did. However it imposes a degree of structure that parents did not bring to their self-descriptions. It also relies upon retrospective reports of how parents felt and what they did. These reports may well involve selective memory and distortion.

In spite of these cautions, it is important to explain why relatively passive or acquiescent coping strategies may be associated with favorable relationships with the medical care staff. Perhaps parents with good medical relationships have less need or desire to exert active control over the medical situation and thus view acceptance of what cannot be changed as an effective coping strategy. For their part, doctors and other medical staff may find it easier to be supportive of parents who are passive rather than active (Taylor, 1979) and may subtly reinforce passive styles through contingent approval and attention. It is especially interesting that parents with higher levels of education report poorer relations with the medical staff than parents with lesser levels of education. To be sure, these same parents reported greater use of precisely those coping strategies that broke from passive patient norms (more information seeking, more problem solving, and less denial). Perhaps parents with higher status and more active coping strategies are more threatening to medical staffs, harder to deal with, harder to control, harder to relate with harmoniously. Because parents with higher levels of education are closer to the professional status of the medical staff they may be less willing to be compliant and to "sit still" in the face of questionable staff behaviors and attitudes. Perhaps too they are more likely to see clearly and discuss openly the uncertain grounds on which all treatment for cancer rests.

These findings on coping effectiveness indicate that parents' evaluations of their own coping are most highly associated with the use of denial as a strategy. In highly stressful situations parents may feel satisfied if they are simply able to keep on going and to ward off excessive pessimism by moderate amounts of denial. Interpreted in this light, moderate amounts of denial can be a healthy and functional response. Lazarus (1981) noted that denial can be detrimental when it reduces vigilance to imminent threats and delays adaptive responding but it may also preserve morale and hope through selective avoidance of pessimistic information. The ability to put things out of their mind may permit parents to return to apparent normality and to triumph over continual worry and despair. Moreover, Featherstone (1980) and Wortman and Dunkel-Schetter (1979) observed that medical staff 
members and close friends often prefer people with cancer to be upbeat and to handle the crisis with equanimity. Parents who are preoccupied may disappoint their friends and experience disapproval and withdrawal from them.

The medical staff's preference for passive parent/patient coping styles may not be conducive to effective long-term adjustment for some patients and their families. Brickman et al. (1982) and others criticized the traditional medical model because of the asymmetrical staff-patient relationships in which the staff unilaterally establish the rules governing behavior in that setting and patients are expected to adopt passive roles (Antonovsky, 1980). Emerging trends in the treatment of childhood cancer, such as the skyrocketing financial burden on parents, increased life expectancy, and reliance on outpatient treatment, are likely to increase the need for parents to monitor medical and psychosocial services and to provide additional care over an extended time period. New partnerships among parents and medical professionals require both to experiment with compatible forms of support and education for active parent roles in the medical care of ill children.

\section{REFERENCES}

American Cancer Society. (1982). Cancer facts and figures. New York: Author.

Antonovosky, A. (1980). Health, stress and coping. San Francisco: Jossey-Bass.

Barbarin, O. (1983). Coping with ecological transitions by black families: a psychosocial model. Journal of Community Psychology, 11, 308-322.

Billings, A., \& Moos, R. (1981). The role of coping responses and social resources in attenuating the stress of life events. Journal of Behavioral Medicine, 4, 139-157.

Binger, C., Ablin, A., Feuerstein, R., Kushner, J., Zuker, S., \& Mikelsen, C. (1969). Childhood leukemia emotional impact on patient and family. New England Journal of Medicine, $280,44-418$.

Brehm, S. (1965). The application of social psychology to clinical practice. Washington, DC: Hemisphere Press.

Brickman, P., Rabinowitz, V., Karuza, J., Coates, D., Cohn, E., \& Kidder, L. (1982). Models of helping and coping. American Psychologist, 32, 368-384.

Cassileth, B., \& Hamilton, J. (1979). Learning to care for the cancer patient: the student dilemma. In B. Cassileth (Ed.), The cancer patient: social and medical aspects of care. Philadelphia: Lea \& Febiger.

Chesler, M., Barbarin, O., Chesler, J., Hughes, D., \& Lebo, J. (1981). Roles of informal networks and medical care organizations. In Helping families cope with childhood cancer: prospects for collaboration. Ann Arbor: University of Michigan, Center for Research on Social Organizations, CRSO Working paper \#243, 1981.

Coyne, J., \& Holroyd, K. (1982). Stress, coping and illness: a transactional perspective. In T. Millon, C. Green, \& R. Meagher (Eds.), Handbook of clinical health psychology. New York: Plenum Press.

DiMatteo, M. R. (1979). A social-psychological analysis of physician-patient rapport. Journal of Social Issues, 35(1), 12-23.

Desmond, H. (1980). Two families: an intensive observation study. In J. Kellerman (Ed.), Psychological aspects of cancer. Springfield: C C Thomas.

Dohrenwend, B., \& Dohrenwend, B. (1974). Stressful life events. New York: Wiley.

Dohrenwend, B. S., Krasnoff, L., Askenasy, A. R., \& Dohrenwend, B. P. (1978). Exemplification of a method for scaling life events: the PERI life events scale. Journal of Health and Social Behavior, 19, 205-229. 
Featherstone, H. (1980). A difference in the family. New York: Basic Books.

Friedman, S. B., Chodoff, P., Mason, J., \& Hamburg, D. (1977). Behavioral observations on parents anticipating the death of a child. In A. Monat \& R. Lazarus (Eds.), Stress and coping (pp. 349-374). New York: Columbia University Press.

Friedson, E. (1970). Professional dominance: the social structure of medical care. New York: Atherton Press.

Futterman, E., \& Hoffman, I. (1973). Crisis and adaptation in the families of fatally ill children. In J. Anthony \& C. Koupernick (Eds). The child in his family: the impact of death and disease (Vol. 2). New York: Wiley.

Holmes, T. H., \& Rahe, R. H. (1967). The social readjustment rating scale. Journal of Psychosomatic Research, 11, 213-218.

Kubler-Ross, E. (1978). On death and dying. New York: Macmillan.

Kupst, M., Schulman, J., Honig, G., Maurer, H., Morgan, E., \& Fochtman, D. (1982). Family coping with childhood leukemia: one year after diagnosis. Journal of Pediatric Psychology, 7, 157-67.

Lazarus, R., (1966). Psychological stress and the coping process. New York: McGraw-Hill.

Lazarus, R. (1981). The costs and benefits of denial. In J. Spinetta \& P. Deasy-Spinetta (Eds.), Living with childhood cancer (pp. 50-67). St. Louis: MO: C. V. Mosby.

Lazarus, R. S., \& Launier, R. (1978). Stress-related transactions between persons and environment. In L. S. Perum \& M. Lewis (Eds.), Perspectives in interactional psychology (pp. 287-327). New York: Plenum Press.

McCubbin, H., \& Patterson, J. M. (1982). Family adaptation to crises. In H. I. McCubbin, A. E. Cauble, \& J. M. Patterson (Eds.), Family stress coping and social support. Springfield, IL: C C Thomas.

McCubbin, H. I., \& Patterson, J. M. (1983). The family stress process: the double ABCX model of adjustment and adaptation. In H. I. McCubbin, M. B. Sussman, \& J. M. Patterson (Eds.), Social stress and the family. New York: Haworth Press.

Seligman, M. (1975). Helplessness. San Francisco: Freeman.

Spinetta, J., Swarner, J., \& Sheposh, J. (1981). Effective parental coping following the death of a child from cancer. Journal of Pediatric Psychology, 6, 251-263.

Stone, G. (1979). Patient compliance and the role of the expert. Journal of Social Issues, 35(1), 34-59.

Taylor, S. (1979). Hospital-patient behavior reactance, helplessness, or control? Journal of Social Issues, 35(1), 156-184.

Taylor, S. (1983). Adjustment to threatening events: a theory of cognitive adaptation. American Psychologist, 38, 1161-1163.

Vaux, K. (1977). Life threatening disease in children. In J. Van Eyes (Ed.), The truly cured child. Baltimore: University Park Press.

Wortman, C. B., \& Dunkel-Schetter, C. (1979). Interpersonal relationships in cancer: A theoretical analysis. Journal of Social Issues, 35, 120-154. 